\title{
Erratum to: An Analysis of Possible Energy Impacts of Automated Vehicles
}

\author{
Austin Brown, Jeffrey Gonder and Brittany Repac
}

\section{Erratum to:}

Chapter "An Analysis of Possible Energy Impacts of Automated Vehicles" in: G. Meyer and S. Beiker (eds.), Road Vehicle Automation, Lecture Notes in Mobility, https://doi.org/10.1007/978-3-319-05990-7_13

In the original version of the book, the title "An Analysis of Possible Energy Impacts of Automated Vehicle" of Chapter 13 has been changed to read as "An Analysis of Possible Energy Impacts of Automated Vehicles". The erratum chapter and the book have been updated with the change.

The updated online version for this chapter can be found at https://doi.org/10.1007/978-3-31905990-7_13 